\section{International Scientific Journal Theoretical \& Applied Science}

\author{
p-ISSN: 2308-4944 (print) e-ISSN: 2409-0085 (online) \\ Year: 2017 Issue: $06 \quad$ Volume: 50
}

Published: $30.06 .2017 \quad \underline{\text { http://T-Science.org }}$
Vladimir Nikolaevich Medvedev

The Teacher Department of Navigation,

The Engineer-mechanic,

State Maritime University Admiral Ushakov, Russia, medvedevsail@gmail.com

SECTION 21. Pedagogy. Psychology. Innovation in Education

\title{
YACHTING - IS THE FACTOR OF DEVELOPMENT OF SOCIAL ACTIVITY OF STUDENTS
}

\begin{abstract}
The basic principles of building an educational system of students engaged in yachting; Reveals the increasing role of students in yachting in the system of maritime vocational education and the lack of development of their practical organizations; The need for modern society in socially active students and the insufficient use of educational opportunities for yachting are analyzed; The need for the development of social activity of young people is shown, without which further economic, political and cultural transformation of the social community is impossible, and the insufficiently developed scientific and methodological support for the basics of practical yachting.

Key words: social activity, students, yachting, professional education, practical organization, marine fleet.

Language: Russian

Citation: Medvedev VN (2017) YACHTING - IS THE FACTOR OF DEVELOPMENT OF SOCIAL ACTIVITY OF STUDENTS. ISJ Theoretical \& Applied Science, 06 (50): 133-138.

Soi: http://s-o-i.org/1.1/TAS-06-50-18 Doi: crossef https://dx.doi.org/10.15863/TAS.2017.06.50.18
\end{abstract}

УДК 372.851

\section{ЯХТИНГ - ФАКТОР РАЗВИТИЯ СОЦИАЛЬНОЙ АКТИВНОСТИ СТУДЕНТОВ}

Аннотация: Рассмотрены основные принциипы построения воспитательной системы студентов, занимающихся яхтингом; раскрывается возрастающая роль занятий студентов яхтингом в системе морского профессионального образования и недостаточная разработанность их практических организаций; анализируется потребность современного общества в социально активных студентах и недостаточное использовании воспитательных возможсностей занятий яхтингом; показывается необходимость развития социальной активности молодежи, без которой невозможно дальнейшее экономическое, политическое и культурное преобразование сочиального сообщества, и недостаточная разработанность научно-методического обеспечения основ практических занятий яхтингом.

Ключевые слова: социильная активность, студенты, яхтинг, профессиональное образование, практическая организация, морской флот.

\section{Introduction}

Ведущие современные педагоги, психологи, философы и социологи считают, что добровольная общественная деятельность молодежи сегодня не только может помочь решить многие социальные проблемы общества, но и способствует развитию социально-значимых качеств личности студентов, формированию у них активной жизненной позиции. Изучение воспитательных возможностей яхтинга приобретают особую актуальность.

Несмотря на существенный интерес к яхтенному движению, аспект развития социальной активности у студентов, занимающихся яхтингом, не рассматривался. До настоящего времени не исследованы воспитательные возможности занятий яхтингом, не разработана эффективная модель развития социальной активности студентов проявляющих интерес к хождению под парусом.

Таким образом, актуальность исследования определяется сложившимися противоречиями между:

- возрастающей ролью занятий студентов яхтингом в системе морского профессионального 
образования и недостаточной разработанностью их практических организаций;

- потребностью современного общества в социально активных студентах и недостаточном использовании воспитательных возможностей занятий яхтингом;

- необходимостью развития социальной активности молодежи, без которой невозможно дальнейшее экономическое, политическое и культурное преобразование социального сообщества, и недостаточной разработанностью научно-методического обеспечения основ практических занятий яхтингом.

\section{Materials and Methods}

Глобальные социальные, экономические, политические и культурные изменения, происходящие в современном российском обществе, предъявляют новые требования к воспитанию подрастающего поколения. В концепции модернизации Российского образования подчёркивается: развивающемуся обществу необходимы инициативные люди, которые могут самостоятельно принимать решения в ситуации выбора, способны к сотрудничеству, отличаются мобильностью, динамизмом, конструктивностью, обладают чувством ответственности, за ее социальноэкономическое процветание. В связи с этим особую актуальность приобретает проблема развития социальной активности молодежи.

Необходимо отметить, что вопросы воспитания социальной активности личности всегда были в центре внимания отечественной педагогики. Востребованные сегодня идеи о воспитании общественной активности подрастающих поколений мы находим в трудах Н.К. Крупской, А.С. Макаренко, В.А. Сухомлинского, С.Т. Шацкого. Современные теоретико-методологические подходы к развитию социальной активности молодежи получили обоснование в работах Б.З. Вульфова, Р.А. Литвак, М.И. Рожкова.

Изучению специфики воспитания социальной активности у школьников на различных этапах их возрастного развития посвящены исследования В.М. Басовой, Т.В. Дуровой, А.В. Зосимовского, Е.К. Касаткиной, Т.Н. Мальковской, А.П. Шпоны и др. В работах Л.П. Клементьева, И.Н. Орловой, В.А. Ситарова, В.А. Сластенина, Э.Д. Тлеулова, Л.А. Трепоуховой рассматриваются социальнопедагогические аспекты развития социальной активности у студентов средних специальных и высших учебных заведений.

В отечественной науке все больше появляется исследований, в которых явление социальной активности личности рассматривается в контексте социализации (А.В.
Волохов, М.В. Демиденко, М.В. Поддубная, Т.Г. Пташко, Л.С. Яковлев и др.), гражданского воспитания (А.В. Беляев, А.С., Гаязов, О.В. Лешер и др.). Причем, их авторы признают, что, несмотря на богатый арсенал средств и методов воспитания социально активной личности, используемых учреждениями образования, особая роль в данном процессе принадлежит детским и молодежным общественным объединениям [1,2].

Вопросам воспитания личности в социально-педагогическом движении детей и молодежи посвящено значительное количество психолого-педагогических исследований. Педагогические и психологические основы деятельности детских и молодежных объединений рассматривались JI.А. Борисовой, С.В. Качалиной, Г.В. Сабитовой, Е.Е. Чепурных и др.; особенности взаимодействия её участников исследовались Т.П. Вернигоровой, А.Ю. Кривокулинским, И.И. Фришман и др.; содержание и методы социального воспитания в общественных объединениях разрабатывались В.А. Дергуновым, Г.В. Ермоленко, С.В. Тетерским, О.Д. Чугуновой и др.; педагогические условия самореализации и саморазвития личности в молодежных объединениях изучались М.Г. Квитковым, В.В. Ковровым, Р.Х. Салахутдиновым.

Ведущие современные педагоги, психологи, философы и социологи считают, что добровольная общественная деятельность молодежи сегодня не только могут помочь решить многие социальные проблемы общества, но и способствовать развитию социальнозначимых качеств студентов, формированию у них активной жизненной позиции. Изучение воспитательных возможностей яхтинга приобретают особую актуальность $[3,4]$.

Несмотря на существенный интерес к яхтенному движению, аспект развития социальной активности у студентов, занимающихся яхтингом, не рассматривался. До настоящего времени не исследованы воспитательные возможности занятий яхтингом, не разработана эффективная модель развития социальной активности студентов проявляющих интерес к хождению под парусом.

Каковы социально-педагогические условия, обеспечивающие эффективность влияния яхтинга на развитие социальной активности молодежи.

Задача выявить, теоретически обосновать и экспериментально проверить эффективность социально-педагогических условий развития социальной активности молодежи в яхтенном движении.

Объект исследования - занятия яхтингом в системе профессионального образования. 
Предмет исследования - социальнопедагогические условия развития социальной активности молодежи в системе профессионального образования.

Ход исследования определялся следующей гипотезой: занятия яхтингом в системе профессионального образования являются фактором развития социальной активности студентов при реализации следующих социальнопедагогических условий:

$$
\text { использование }
$$

личностноориентированных технологий развития социальной активности студентов;

- свободный выбор студентами видов и форм социально значимой деятельности;

- педагогическая поддержка перехода процесса развития социальной активности в режим саморазвития за счет актуализации мотивационной сферы студентов и их выхода в рефлексивную позицию.

В соответствии с целью и гипотезой в исследовании ставились следующие задачи:

- Выявить и обосновать зависимость развития молодежной социальной активности студентов от её участия в занятиях яхтингом.

- Уточнить сущность понятия «занятия яхтингом» и определить его воспитательные возможности в развитии социальной активности студентов, функции и принципы.

- Выявить и экспериментально проверить социально-педагогические условия развития социальной активности студентов.

- Разработать структурно-функциональный модуль развития социальной активности студентов - участников яхтенного движения.

Для решения поставленных задач и проверки выдвинутой гипотезы использовались следующие методы исследования. Теоретические методы: анализ нормативных документов в сфере образования, историко-педагогический анализ, теоретико-методологический анализ, понятийнотерминологический анализ, системный анализ. Эмпирические методы: исследование и обобщение эффективного опыта студенческих общественных объединений, констатирующий эксперимент, формирующий эксперимент, наблюдение, анкетирование, тестирование, экспертное оценивание, статистические методы обработки данных и проверки выдвигаемой гипотезы.

Научная новизна исследования состоит в том, что:

- доказана взаимозависимость уровня развития социальной активности студентов от участия в занятиях яхтингом;

- разработан модуль развития социальной активности студентов, представляющий собой логически завершенную последовательность этапов личностного роста студентов, целостность которого обеспечена единством структурных (цель, принципы, содержание, технологии) и функциональных (аксиологическая, адаптирующая, передача культурного наследия, компенсаторная, регулятивная) компонентов.

- определены критерии и уровни развития социальной активности студентов занимающихся яхтингом.

Теоретическая значимость исследования заключается в том, что:

- расширены научные представления о занятиях яхтингом и его воспитательных возможностях в развитии социальной активности студентов;

- уточнена характеристика понятия «занятия яХтингом»;

- определены принципы реализации модуля развития социальной активности студентов при занятиях яхтингом, обеспечивающие её результативность.

В ходе исследований были выявлены следующие положения:

1. Студенческий яхтинг - это добровольная форма объединения для мобилизации социальной инициативы, достижения общественно значимых целей, совместного решения общих проблем, способствующая личностному росту его участников и развитию социальной активности студентов.

2. Возможности занятий яхтингом в развитии социальной активности студентов обусловлены реализацией принципов: добровольностью включения студентов в различные виды социально-ценной деятельности; правом выбора средств достижения целей при совместном решении проблем; признанием равенства личных и общественных потребностей; осознанием собственной социальной защищённости студентов при готовности защищать интересы других; сочетанием самоуправления с последовательным развитием демократических начал в управлении; неформальностью, нестандартностью содержания деятельности; разновозрастным составом участников; целенаправленным использованием обучения и воспитания как средства достижения социально значимых целей и личностного роста студентов.

3. Модуль развития социальной активности студентов, представляет собой логически завершенную последовательность этапов личностного роста студентов, целостность которого обеспечена единством структурных (цель, принципы, содержание, технологии) и функциональных (аксиологическая, адаптирующая, передача культурного наследия, компенсаторная, регулятивная) компонентов. Данный модуль реализуется с учетом принципов добровольности, самоактуализации, 
индивидуальности, субъектности, творчества и поддержки.

4. Эффективность развития социальной активности студентов определяется социальнопедагогическими условиями:

- использование ориентированных технологий развития социальной активности студентов;

- свободный выбор студентами видов и форм социально значимой деятельности;

- педагогическая поддержка перехода процесса развития социальной активности в режим саморазвития за счет актуализации мотивационной сферы студентов и их выхода в рефлексивную позицию.

Изучение современного состояния проблемы развития социальной активности студентов, анализ психолого-педагогический литературы, опыт работы в волонтерском движении, проведенное нами исследование показали, что добровольная общественная деятельность студентов сегодня не только может помочь решению многих социальных проблем общества, но и способствовать развитию социально-значимых качеств юношей и девушек, формированию у них активной жизненной позиции [5,6].

Отправной точкой исследования явилось уточнение понятия «занятия яхтингом», которое было соотнесено с такими понятиями, как «парус - как образ жизни», «студенческий яхтинг», и определено как добровольная форма объединения для мобилизации социальной инициативы студентов, достижения общественно значимых целей, совместного решения общих проблем, способствующая личностному росту его участников и развитию социальной активности у студентов. Проанализировав сущность занятий яхтингом, было установлено, что его воспитательные возможности в развитии социальной активности студентов обусловлены: добровольностью включения студентов в различные виды социально - ценностной деятельности; правом выбора средств достижения цели при совместном решении проблем; признанием равенства личных и общественных потребностей; осознанием собственной социальной защищенности студентов в их готовности защищать интересы других; сочетанием самоуправления с последовательным развитием демократических начал в управлении; неформальностью, нестандартность содержания деятельности; целенаправленным использованием обучения и воспитания как средства достижения социально значимых целей и личностного роста студентов $[7,8]$.

Исходя из воспитательных возможностей занятий яхтингом, на основе системного и личностно - деятельностного подходов был разработан структурно - функциональный модуль развития социальной активности студентов участников занятий яхтингом. Он характеризуется наличием пяти этапов личностного роста (выбора и самопознания, самосовершенствования, самоопределения, самореализации, творческого роста). Целостность модуля обеспечена единством структурных (цель, содержание, принципы, технологии) и функциональных (аксиологический, адаптирующий, передачи культурного наследия, компенсаторный, креативный, регулятивный) компонентов $[9,10]$.

Проведенное исследование показало, что данный модуль эффективно функционирует в определенных социально-педагогических условиях, к которым относятся: использование личностно-ориентированных технологий развития социальной активности молодежи; свободный выбор студентами видов и форм социально значимой деятельности; педагогическая поддержка перехода процесса развития социальной активности в режим саморазвития за счет актуализации мотивационной сферы студентов и их выхода в рефлексивную позицию.

Для получения объективной информации об уровне развития социальной активности молодежи - участников занятий яхтингом - нами была выделена система взаимосвязанных критериев и показателей, включающая: мотивационный критерий, показателями которого выступают сформированность социально значимых мотивов, потребность в социально - ценностной деятельности, направленность на достижение результатов в социальной деятельности; когнитивный критерий, показателями которого являются наличие знаний о различных типах социальных отношений, особенностях социального общения, наличие практических знаний и умений, необходимых для проявления активности в той или иной деятельности; деятельностный критерий, показателями которого служат характер включения в социально значимую деятельность, проявление инициативы, самостоятельности и ответственности в деятельности, способность к преодолению трудностей.

В исследовании были получены данные, научная новизна и теоретическая значимость которых заключается в том, что расширены научные представления о занятиях яхтингом и их воспитательных возможностях в развитии социальной активности студентов; уточнена характеристика понятия «занятия яхтингом»; разработан модуль развития социальной активности молодежи, определены принципы 
самореализации студентов; определены критерии и уровни развития социальной активности студентов в студенческом яхтенном движении. Основной целью опытно-экспериментальной работы явилась проверка эффективности социально-педагогических условий развития социальной активности студентов в студенческом яхтенном движении.

\section{Conclusion}

Проведённое

теоретическое

и экспериментальное исследование подтвердило выдвинутую гипотезу и позволило сделать следующие выводы:

1. Студенческий яхтинг - это добровольная форма объединения для мобилизации социальной инициативы, достижения общественно значимых целей, совместного решения общих проблем, способствующая личностному росту его участников и развитию социальной активности студентов.

2. Структурно - функциональный модуль развития социальной активности студентов в занятии яхтингом, построенный на положениях системного и личностно -деятельностного подходов, представляет собой логически завершенную последовательность этапов личностного роста (выбора и самопознания, самосовершенствования, самоопределения, самореализации, творческого роста). Целостность модуля обеспечена единством структурных (цель, содержание, принципы, технологии) и функциональных (аксиологический, адаптирующий, передачи культурного наследия, компенсаторный, креативный, регулятивный) компонентов.

3. Воспитательные возможности занятий яхтингом в развитии социальной активности студентов обусловлены следующими принципами: добровольностью включения студентов в различные виды социальноценностной деятельности; правом выбора средств достижения целей при совместном решении проблем; признанием равенства личных и общественных потребностей; осознанием собственной социальной защищенности студентов при готовности защищать интересы других; сочетанием самоуправления с последовательным развитием демократических начал в управлении; неформальностью, нестандартностью содержания деятельности; целенаправленным использованием обучения и воспитания как средства достижения социально значимых целей и личностного роста студентов.

4. Социально-педагогические условия (использование личностно-ориентированных технологий развития социальной активности студентов; свободный выбор студентами видов и форм социально значимой деятельности; педагогическая поддержка перехода процесса развития социальной активности в режим саморазвития за счет актуализации мотивационной сферы студентов и их выхода в рефлексивную позицию) обеспечивают эффективное развитие социальной активности молодежи в студенческом яхтинге.

5. Обоснованные критерии (мотивационный, когнитивный, деятельностный) обеспечили возможность количественно и качественно измерить произошедшие изменения в уровне развития социальной активности студентов участников занятий яхтингом. Проведённые эксперименты показали существенное повышение социальной активности студентов во всех экспериментальных группах. Наиболее высокие результаты наблюдались в группе, где модуль реализовывался на фоне комплекса условий.

Данное исследование не исчерпывает содержания рассматриваемой проблемы. Перспективными направлениями её дальнейшего развития могут стать: использование вариативнопрограммного подхода в подготовке студентов; развитие творческого потенциала личности в результате занятий яхтингом.

\section{References:}

1. Ananev BG (1969) Chelovek kak predmet poznaniya. JL: Izd-vo LGU, 1969. - 339 p.

2. Andreeva GM (1988) Socialnaya psixologiya. M.: Izd-vo MGU, 1988. - 415 p.

3. Andrienko EV (2000) Socialnaya psixologiya: Uchebnoe posobie dlya studentov vyssh. ped. ucheb. zavedenij. M.: Akademiya, 2000. - 264 p.
4. Blauberg IV, Yudin EG (1973) Stanovlenie i sushhnost sistemnogo podxoda. -M.: Nauka, 1973. $-270 \mathrm{p}$.

5. Vulfov BZ (1994) Sem paradoksov vospitaniya. -M.: Novaya shkola, 1994.-78 p.

6. Vygotskij JC (2000) Psixologiya. M.: EksmoPress, 2000. - 386 p. 


\begin{tabular}{l|lrl|l|ll} 
& ISRA (India) & $=\mathbf{1 . 3 4 4}$ & SIS (USA) & $=\mathbf{0 . 9 1 2}$ & ICV (Poland) & $=\mathbf{6 . 6 3 0}$ \\
Impact Factor: & ISI (Dubai, UAE) $=\mathbf{0 . 8 2 9}$ & PUHL (Russia) $=\mathbf{0 . 2 3 4}$ & PIF (India) & $=\mathbf{1 . 9 4 0}$ \\
& GIF (Australia) & $\mathbf{0 . 5 6 4}$ & ESJI (KZ) & $=3.860$ & IBI (India) & $=\mathbf{4 . 2 6 0}$ \\
& JIF & $\mathbf{1 . 5 0 0}$ & SJIF (Morocco) & $=\mathbf{2 . 0 3 1}$ & & \\
\hline
\end{tabular}

7. Kagan MS (1974) Chelovecheskaya deyatelnost: opyt sistemnogo analiza. M.: Politizdat, 1974. - 328 p.

8. Rubinshtejn SJ (1976) Problemy obshhej psixologii. 2-e izd. - M.: Pedagogika, 1976. $416 \mathrm{p}$.

9. Suxomlinskij VA (1981) Metodika vospitaniya kollektiva. M.: Prosveshhenie, 1981.-192 p.
1. Mishchik SA (2015) Pedagogometrik - science and academic subject. Materialy Mezhdunarodnoy nauchnoy konferenctsii "European Technology in Science" 28.02.2015. ISJ Theoretical \& Applied Science 02 (22): 103-106 Malmö, Sweden. doi: http://dx.doi.org/10.15863/TAS.2015.02.22.17 